\title{
A PROPOSED LEAN DECISION-MAKING PROCESS FOR BUILDING ENERGY RETROFITS
}

\author{
Xiaosu Ding ${ }^{1}$, Kristen Parish ${ }^{2}$
}

\begin{abstract}
Buildings are one of the largest contributors of greenhouse gas emissions and, in the United States, they are the largest energy users. To combat these emissions, policy makers suggest retrofitting older buildings to achieve better energy performance. (The authors define retrofit as any changes to an existing building that improve the building's ability to perform or extend the building's life.) Despite consensus that buildings should be retrofit, building owners may struggle to identify how to retrofit their building. This paper addresses this gap by providing a proposed lean process, rooted in Choosing by Advantages (CBA), for selecting among potential energy retrofit options.

In this paper, the authors present the energy retrofit decision-making process recommended by the U.S. Department of Energy and compare it to those used in practice on case studies completed in the last five years. The authors identified two shortcomings in the implemented processes: first, the decision-making processes only consider the designers' perspective on energy and cost savings with little involvement from other stakeholders, and thus, they may ignore the needs, desires, and opinions of others with non-design backgrounds; second, these processes consider more design alternatives than may be realistic for a building owner given budget and schedule constraints.

To make the process leaner, the authors propose a new energy retrofit decisionmaking process, rooted in CBA, that addresses the previously-identified shortcomings. This process involves more stakeholders in the decision-making process. Moreover, this process helps decision-makers focus on the most promising design alternatives, thereby supporting better use of time and increased likelihood of a successful retrofit.
\end{abstract}

\section{KEYWORDS}

Building energy retrofit, multi-criteria decision making, choosing by advantage (C BA), design science, work flow

\section{INTRODUCTION}

Buildings impact the environment, society and humans. Buildings are estimated to use about $40 \%$ of the total energy worldwide and produce $30 \%$ of anthropogenic green gas (GHG) (United Nations, 2009) throughout their lifecycle. Over a building's lifecycle,

1 Master Student, School of Sustainable Engineering and the Built Environment, Arizona State University, Tempe, AZ, 85281, +1 602545 4021, xding16@asu.edu

2 Associate Professor, School of Sustainable Engineering and the Built Environment, Arizona State University, Tempe, AZ, 85281, Kristen.Parrish@asu.edu 
the operation stage is responsible for most of the energy and water use, as well as for the bulk of the greenhouse gas (GHG) emissions. Thus, reducing the environmental impact of buildings represents an opportunity to mitigate the impacts of climate change, and one method to reduce impacts is to retrofit existing buildings. The United States Department of Energy (US DOE) defines an energy retrofit as, "an opportunity to upgrade the energy performance of commercial building assets for their ongoing life. Often retrofit involves modifications to existing commercial buildings that may improve energy efficiency or decrease energy demand." (US DOE, 2019)

Indeed, policy makers recognize the value of retrofitting existing buildings when they develop goals for building energy consumption. For example, the California Energy Efficiency Strategic Plan proposed that: " $50 \%$ of commercial buildings will be retrofit to Zero Net Energy by 2030" (DNV GL, 2017). While nearly every building offers the potential to improve its energy performance, not every building is a good candidate for an energy retrofit, particularly if the building is nearing the end of its useful life (Maslesa et al., 2018).

In this paper, the authors present the energy retrofit decision-making process recommended by the U.S. Department of Energy. The authors compare this to the decision-making processes used in practice, as documented in building energy retrofit case studies. Then, one new decision-making process is proposed incorporating the method of Choosing by Advantages (CBA) (Suhr, 1999; Kpamma et al., 2014), which proves to be a better decision-making tool than weighting tools for an energy design problem (Correa et al., 2017).

The rest of this paper is organized as follows: the authors present the energy retrofit decision making process recommended by the U.S. Department of Energy in the literature review section. The methodology section discusses how the authors review and summarize case studies; the authors then summarize case studies and their common decision-making process features. The authors propose a new energy retrofit decisionmaking process rooted in CBA. The authors also compare the new decision-making process with those in case studies and U.S. DOE; finally, the paper closes with a discussion of conclusions and future work.

\section{LITERATURE REVIEW: ENERGY RETROFIT PROCESS}

A building energy retrofit project is often complex and made of multi-steps, in some cases addressing multiple building systems (e.g., lighting and heating). Figure 1 illustrates the U.S. Department of Energy's energy retrofit process (Hendron, R.; Leach, M.; Bonnema, E.; Shekhar, D.; Pless, 2013; Hendron, Leach, Bonnema, Shekhar, \& Pless, 2013). Figure 1 illustrates a five-step process, where the first three steps relate to how to decide what energy retrofit(s) to implement. The first step, goal setting, involves determining the energy goals for the project, which can either be absolute, i.e., "the office spaces in this building will consume $85 \mathrm{kWh} /$ square meter/year" or relative, i.e., "the office spaces will realize energy consumption reductions of $20 \%$." Following goal setting, the DOE process moves to "action creating," where designers develop a set of energy efficiency measures (EEMs) that can be installed in the building to meet the goals. Notably, this step involves designers and owners, but rarely building users or constructors. Next, the designers evaluate the EEMs they developed during the "action creating" step, and determine a set of EEMs they feel make the most sense for the building, based on financing available for the retrofit, the goals, and the cost- 
effectiveness of the EEMs. Surprisingly, the step "action creating" is ahead of "Financing options evaluation" and there is no loop to circle back to the original design (action plan). Moreover, after evaluating financing, say, to meet the budget requirement, the design is done and the process moves on to the "implementation approach," where the retrofit is constructed; "project completion" includes commissioning the retrofit and closing out the project.

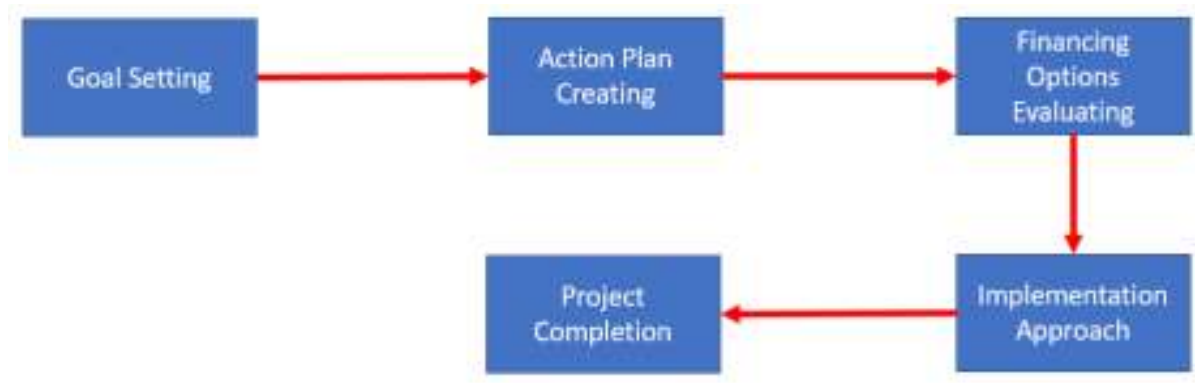

Figure 1: Energy retrofit process recommended by U.S. Department of Energy, created based on the energy retrofit guide (Hendron, R.; Leach, M.; Bonnema, E.; Shekhar, D.; Pless, 2013)

Figure 2 presents a more detailed view of the "action plan creating" step in Figure 1. Figure 2 illustrates the "Staged Approach to Energy Efficiency Upgrade" (Hendron, R.; Leach, M.; Bonnema, E.; Shekhar, D.; Pless, 2013; Hendron et al., 2013). Designers review the existing building's performance and first try to improve what is already there ("existing building commissioning"). Then, designers develop retrofits for specific systems designed to reduce the building's load on the energy grid (load-based retrofit measures"). Finally, designers consider the air and water systems, and then the heating and cooling systems, to develop additional EEMs that may synergize well with the load-based retrofit measures. For example, if a load-based retrofit measure calls for installing more efficient lighting systems, the heating and cooling retrofit may downsize the existing air conditioning units, given that the lights now create less heat in the building. The designers follow the flow chart and study the potential retrofit measures step by step, and all retrofits will be included in the "action plan" from Figure 1 if the financing evaluation proves feasible. Therefore, the energy retrofit decision-making process recommended by the U.S. Department of Energy leads designers and building owners to go over the pre-defined energy systems (like the lighting and cooling systems) one by one and identify their energy saving potentials. After analysing the costs and benefits for each system, the designers develop an energy retrofit plan.

It could be convenient to apply this process for making energy retrofit decisions. However, with the process' simplicity, there could be three potential problems. First, the decisions may be limited to the pre-defined energy retrofit choices, which could impact the performance of the energy retrofit. Second, there is no involvement of stakeholders from different backgrounds (e.g., building occupants or constructors) who could make contributions (e.g., recommendations, criticisms) to the projects. Finally, the evaluation system considers only the financial benefits, rather than also including other benefits, like improved occupant comfort or productivity. 


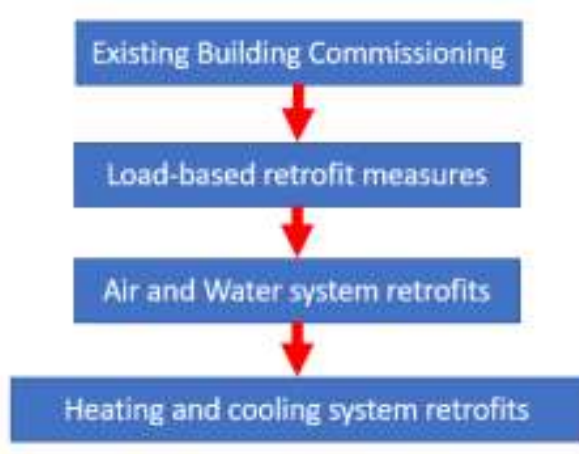

Figure 2: A staged approach to Energy Efficiency Upgrades recommended U.S. Department of Energy, created based on the energy retrofit guide (Hendron, R.; Leach, M.; Bonnema, E.; Shekhar, D.; Pless, 2013)

\section{METHODOLOGY}

For this article, the authors searched the Web of Science (WoS) for papers using "decision-making" and "building energy retrofit" as keywords. This search yielded literature used to collect information about the decision-making processes actually used for making building energy retrofit decisions, as documented in energy retrofit case studies. The authors only considered papers published in the last five years to limit the scope of inquiry. Table 1 lists the results of these searches.

Table 1: Results of Literature Search

\begin{tabular}{ccc}
\hline Search terms & Number of research papers & $\begin{array}{c}\text { Number of case } \\
\text { studies }\end{array}$ \\
\hline $\begin{array}{c}\text { "Building energy } \\
\text { retrofit" and } \\
\text { "decision-making" }\end{array}$ & 53 & 30 \\
\hline
\end{tabular}

The authors reviewed the case studies and compared the decision-making processes used in each to summarize an energy retrofit decision-making process. In every case study, we assessed the following:

1. How building energy performance after retrofit was predicted;

2. How decision-makers evaluated the financial costs and benefits;

3. Who made the final decision on what to implement in the retrofit and how they selected those retrofit measures.

After reviewing and summarizing the decision-making processes, the authors look for shortcomings in these processes; that is, the authors looked for waste in the case studies. In the event that retrofits did not meet their goals, the authors conducted a root cause analysis () to determine why energy targets were not achieved. These observations formed the basis of the authors' proposed process. The authors sought to mitigate the failures of the current process through developing a new, CBA-based decision-making process for developing and selecting EEMs for energy retrofits. 


\section{CURRENT STATE: THE ENERGY RETROFIT DECISION MAKING PROCESS}

Figures 1 and 2 illustrate that designers need to consider retrofit measures in predefined building systems, determine those that are financially advantageous, and then move forward with a retrofit. This suggests that the energy retrofit decision-making process comprises three important features:

1. How to predict possible building energy performance after retrofits;

2. How to evaluate the financial costs and benefits;

3. How to make the final decision, that is to select the retrofit measures.

\section{Case Study Review}

In this section, the authors analyse thirty (30) case studies from literature to find out how these three features manifest in practice. This analysis allows the authors to plot the basics of the energy retrofit decision-making processes documented in the literature of the last five years.

Table 2 lists the three features of each case study. First, there are two ways to calculate the energy performance, energy codes and energy modelling. By using energy codes, the researchers used the guidance and codes to estimate the potential energy consumption after energy retrofits. For example, EN ISO 13790 was applied to calculate the energy consumption of existing and future buildings (Qian Wang, et al., 2017). On the other hand, more researchers chose energy models to simulate the energy consumption following an energy retrofit. One popular energy modelling software is "EnergyPlus," which predicts the performance of energy retrofit measures from multiple case studies (Ashrafian et al., 2016; Mauro et al.,2017; Tagliabue et al., 2018; Qinpeng Wang et al., 2017).

Table 2: Approaches for Energy Prediction, Cost Evaluation, and Selection of EEMs

\begin{tabular}{ccc}
$\begin{array}{c}\text { Predicting Energy } \\
\text { Consumption } \\
\text { (post-retrofit) }\end{array}$ & Cost Evaluation Methods & $\begin{array}{c}\text { Methods to select EEMs } \\
\text { for installation }\end{array}$ \\
\hline Energy code & Life cycle analysis & Selecting all measures \\
$\begin{array}{c}\text { Energy simulation } \\
\text { model }\end{array}$ & Payback period & Weighting \\
& Net present value & Optimization \\
\hline
\end{tabular}

Second, most case studies (23 of 30) used financial models to evaluate the retrofit's economic performance, although in the other case studies, authors simply calculated the energy savings number, as was suggested in the US Department of Energy guides described in the previous section. The authors note three popular approaches for financial evaluation: life cycle cost (Amiri et al., 2018; Becchio et al., 2016; Jafari 2017; Qian Wang et al., 2014), payback period (Aguacil et al.,2017; Ashrafian et al., 2016; Tahsildoost et al., 2015), and net present value (Becchio et al., 2016;

Hosseinian et al., 2017; Senel Solmaz et al., 2018; Qinpeng Wang et al., 2017). All of these approaches focus on the economic benefits of the life-long service of the building, say, the energy savings from daily operation subtracting the initial cost of retrofit projects. 
Finally, different methods were used to make the final decision of what EEMs to include in the retrofit. In some studies, the candidate retrofit plans were simply ranked based on the energy or cost saving (Ashrafian et al., 2016; Becchio et al., 2016; Fregonara et al., 2017; Hosseinian et al., 2017). Other case studies used weighting methods to find the most applicable retrofit plan, where Analytic Hierarchy Process (AHP) is one popular tool (Amiri et al., 2018; McArthur et al., 2016; Rocchi et al., 2018; Si et al., 2018; Si et al., 2016; Zheng et al., 2019). Finally, a few case studies had multiple choices in every retrofit measure; these case studies used optimization algorithms to find the best EEM combination for the final plan (Mauro et al., 2017; Senel Solmaz et al., 2018).

\section{ObSERVATIONS FROM CASE STUDIES}

After reviewing the energy retrofit decision-making process, the authors note several observations. Unlike the retrofit process recommended by the U.S. DOE, most case studies documented exploring multiple energy retrofit measures, especially when they used energy simulation software. In fact, with energy modelling, the designers can predict the building performance after retrofit. With more retrofit options to choose from, more variables would be considered and thus, the decision-making tools that allow designers to make selections among a larger and more complex design space become all the more important. Finally, when reviewing case studies, it seems that even when designers consider a more complex design space, with multiple retrofit measures that may be interdependent, the decision criteria remain relatively simplistic, based exclusively on the economic variables (i.e., benefits and cost).

The authors identify two shortcomings from the US DOE and case study decision making processes. First, the decision makers focus on the economic variables and do not pay enough attentions on needs from the stakeholders of different backgrounds. Second, based on the idea of the weighting or optimization, designers need to create a large design space to cover every possible design and compare them. In this way, efforts (energy modelling and cost analysis) could be wasted on design alternatives that may easily be deemed infeasible from others' perspectives; for example, the procurement staff for the building may quickly rule out an alternative, based on the fact that there is only a single vendor of that system, which violates procurement rules.

\section{LEANER RETROFIT DECISION-MAKING PROCESS}

Considering the aforementioned shortcomings, the authors propose a leaner retrofit decision-making process that enhances the involvement of stakeholders and supports more holistic review of alternatives, rooted in CBA (e.g., Kpamma et al., 2014; Soundet al., 2015). Figure 3 shows this process; it uses CBA in a design charrette environment (Correa et al., 2017). The words in chevrons describe the energy retrofit process; text below maps the process to the CBA process and vocabulary (Koga, 2008).

The first three (3) steps are preparation phases for the decision-making charrette (in Step 4). In step 1, the stage-setting phase of CBA is performed and the project team determines who should participate in charrettes (i.e., form the decision-making team). The building owner builds the decision-making team, which should include stakeholders with different backgrounds, like designers, owners, users, and contractors. This team works together to develop alternatives, factors, and criteria (as described in 
Suhr, 1999). In this phase, the decision-making team will also learn CBA if they do not already know it.

\begin{tabular}{|c|c|c|c|c|}
\hline $\begin{array}{c}\text { Charrette } \\
\text { member crating }\end{array}$ & $\begin{array}{l}\text { Measures } \\
\text { deciding }\end{array}$ & $\begin{array}{l}\text { Design } \\
\text { alternatives } \\
\text { generating }\end{array}$ & & $\begin{array}{l}\text { Retrofit plan } \\
\text { delivered }\end{array}$ \\
\hline $\begin{array}{l}\text { - CBA stage-setting } \\
\text { phase: } \\
\text { - Identify the } \\
\text { stakeholders } \\
\text { - Identify the interest } \\
\text { and criteria }\end{array}$ & $\begin{array}{l}\text { - CBA innovation } \\
\text { phase I: } \\
\text { - Create the } \\
\text { possibilities }\end{array}$ & $\begin{array}{l}\text { - CBA innovation } \\
\text { phase II: } \\
\text { - Determine the } \\
\text { attributes of } \\
\text { alternatives and } \\
\text { thus, advantages }\end{array}$ & $\begin{array}{l}\text { - CBA decision- } \\
\text { making phase: } \\
\text { - Decide the } \\
\text { importance of each } \\
\text { advantage } \\
\text { - Choose the prefered }\end{array}$ & $\begin{array}{l}\text { - CBA reconsideration } \\
\text { phase: } \\
\text { - Check and evaluate } \\
\text { before the delivery }\end{array}$ \\
\hline
\end{tabular}

Figure 3 the proposed energy retrofit decision-making process

In Step 2, the team determines factors and alternatives (in this case, energy retrofit measures). Designers would likely provide the bulk of the alternatives, but other team members can also provide alternatives. When the retrofit measure alternatives are collected, the decision-making process moves to Step 3.

In Step 3, members may propose different decision factors for the decision-making charrette (note cost will likely be one of the factors). During this step, the design team builds the energy model with different retrofit measures implemented to estimate building energy performance with any combination of retrofit measures (the building performance is an attribute of an alternative). The team can work together to identify the attributes of each alternative, and assess advantages from these attributes. In this step, any alternative without advantages will be removed. The total number of alternatives are limited to twenty (20) for the decision-making charrette. If design alternatives cannot meet the requirements of decision-making team, the process can loop back Step 2 and generate new retrofit measure alternatives.

In Step 4, the design team hosts a decision-making charrette to decide the final energy retrofit plan. In the charrette, every team member will independently assess the available design alternatives with importance of advantages (IoA) (Correa et al., 2017). At the end, the final retrofit plan is decided by the trade-off between the cost and IoA.

In the final step, the energy retrofit plan is delivered for construction.

\section{COMPARISON OF PROPOSED AND DOE PROCESSES}

Compared to the U.S. DOE decision-making process for energy retrofits, the leaner decision-making process could meet the requirements of different stakeholders (owners, occupants, contractors, designers and so on). Moreover, rather than only focusing on only energy savings and cost, the proposed process offers an opportunity to consider additional factors, like occupant comfort, in the comparison of retrofit measure alternatives. Finally, in including more stakeholders in the alternative generation process, the proposed process supports inclusion (and exclusion) of alternatives that may be outside of the traditional design considerations.

Using CBA, decision-making efforts are leaner because they focus on evaluating all alternatives and deciding the most promising design alternatives in the decisionmaking charrette. In fact, designs that do not have any advantages would be removed prior to the decision-making charrette. This seems better than the processes in literature 
because the latter processes may waste resources on alternatives without advantages when investing the resources uniformly into every alternative.

In fact, the CBA decision-making process is proven to have a better performance than the decision-making process of "weighting, rating and calculating" (Correa et al., 2017), and the latter type of process is used by most of reviewed case studies in literatures.

\section{CONCLUSION AND FUTRUE RESEARCH}

In this paper, the authors presented the energy retrofit decision-making process recommended by the U.S. Department of Energy and compared this to decision-making processes documented in case studies published in the last five years. Two shortcomings are found in these processes: first, the decision-making processes only consider the design about the energy savings and costs with little involvement of different stakeholders, and thus, they may ignore the opinions from other backgrounds; second, too much time could be spent on the design alternatives that would be infeasible, as they do not have any advantages.

To make the process leaner, the authors presented a new energy retrofit decisionmaking process that leverages CBA. With this new process, the stakeholders from different backgrounds can get involved in the decision-making process or even make contributions to the set of retrofit design options. Moreover, most decision-making efforts are used to evaluate and compare promising design alternatives in the decisionmaking charrette. Therefore, the final retrofit may have better performance.

For future work, the authors plan to evaluate the performance of the proposed decision-making process in upcoming energy retrofit projects. This will allow the authors to determine whether or not this process yields advantageous energy performance compared to other processes. Finally, in piloting this process, the authors can refine the decision-making process as required.

\section{REFERENCES}

Aguacil, S., Lufkin, S., Rey, E., \& Cuchi, A. (2017). Application of the cost-optimal methodology to urban renewal projects at the territorial scale based on statistical data-A case study in Spain. Energy and Buildings, 144, 42-60. https://doi.org/10.1016/j.enbuild.2017.03.047

Amiri Fard, F., \& Nasiri, F. (2018). Integrated Assessment-Optimization Approach for Building Refurbishment Projects: Case Study of Passive Energy Measures. Journal of Computing in Civil Engineering, 32(5), 05018003. https://doi.org/10.1061/(asce)cp.1943-5487.0000785

Ashrafian, T., Yilmaz, A. Z., Corgnati, S. P., \& Moazzen, N. (2016). Methodology to define cost-optimal level of architectural measures for energy efficient retrofits of existing detached residential buildings in Turkey. Energy and Buildings, 120, 5877. https://doi.org/10.1016/j.enbuild.2016.03.074

Becchio, C., Ferrando, D. G., Fregonara, E., Milani, N., Quercia, C., \& Serra, V. (2016). The cost-optimal methodology for the energy retrofit of an ex-industrial building located in Northern Italy. Energy and Buildings, 127, 590-602. https://doi.org/10.1016/j.enbuild.2016.05.093 
Correa, M. G., Arroyo, P., Mourgues, C., \& Flager, F. (2017). Comparing Choosing by Advantages and Weighting, Rating and Calculating Results in Large Design Spaces. 25th Annual Conference of the International Group for Lean Construction, (July), 259-266. https://doi.org/10.24928/2017/0248

DNV GL. (2017). Residential Zero Net Energy Building Integration Cost Analysis.

Fregonara, E., Giordano, R., Ferrando, D. G., \& Pattono, S. (2017). EconomicEnvironmental Indicators to Support Investment Decisions: A Focus on the $\begin{array}{lllll}\text { Buildings' } \quad \text { End-of-Life } & \text { Stage. } & \text { Buildings, } & 7(4), & 65 .\end{array}$ https://doi.org/10.3390/buildings7030065

Hendron, R.; Leach, M.; Bonnema, E.; Shekhar, D.; Pless, S. (2013). Advanced Energy Retrofit Guide: Practical Ways to Improve Energy Performance; Grocery Stores (Revised)(Book). Retrieved from http://www.osti.gov/scitech/biblio/1045045\%5Cnfile:///C:/Users/tsayed/Google Drive/Retrofit/doe_eere_aerg_office_buildings.pdf

Hendron, R., Leach, M., Bonnema, E., Shekhar, D., \& Pless, S. (2013). Advanced Energy Retrofit Guide for Healthcare Facilities. Retrieved from https://www.nrel.gov/docs/fy13osti/57864.pdf

Hosseinian, S., Choi, K., \& Bae, J. (2017). IRIER: A Decision-Support Model for Optimal Energy Retrofit Investments. Journal of Construction Engineering and Management, 143(9), 05017016. https://doi.org/10.1061/(asce)co.19437862.0001362

Jafari, A., \& Valentin, V. (2017). An optimization framework for building energy retrofits decision-making. Building and Environment, 115, 118-129. https://doi.org/10.1016/j.buildenv.2017.01.020

Koga, J. (2008). Introductory Guidelines to Sound Decisionmaking, 9.

Kpamma, Z. E., Adjei-Kumi, T., Ayarkwa, J., \& Adinyira, E. (2014). Enhancing UserInvolvement Through a Multi-Criteria Decision Aid: A Lean Design Research Agenda. Proceedings for the 22nd Annual Conference of the International Group for Lean Construction., 487-496.

Maslesa, E., Jensen, P. A., \& Birkved, M. (2018). Indicators for quantifying environmental building performance: A systematic literature review. Journal of Building Engineering, 19(March), 552-560. https://doi.org/10.1016/j.jobe.2018.06.006

Mauro, G. M., De Masi, R. F., Vanoli, G. P., Bianco, N., \& Ascione, F. (2017). Resilience of robust cost-optimal energy retrofit of buildings to global warming: A multi-stage, multi-objective approach. Energy and Buildings, 153, 150-167. https://doi.org/10.1016/j.enbuild.2017.08.004

McArthur, J. J., \& Jofeh, C. G. H. (2016). Portfolio retrofit evaluation: A methodology for optimizing a large number of building retrofits to achieve triple-bottom-line objectives. Sustainable Cities and Society, 27, 263-274. https://doi.org/10.1016/j.scs.2016.03.011

Nielsen, A. N., Jensen, R. L., Larsen, T. S., \& Nissen, S. B. (2016). Early stage decision support for sustainable building renovation - A review. Building and Environment, 103, 165-181. https://doi.org/10.1016/j.buildenv.2016.04.009

Rocchi, L., Kadziński, M., Menconi, M. E., Grohmann, D., Miebs, G., Paolotti, L., \& Boggia, A. (2018). Sustainability evaluation of retrofitting solutions for rural 
buildings through life cycle approach and multi-criteria analysis. Energy and Buildings, 173, 281-290. https://doi.org/10.1016/j.enbuild.2018.05.032

Senel Solmaz, A., Halicioglu, F. H., \& Gunhan, S. (2018). An approach for making optimal decisions in building energy efficiency retrofit projects. Indoor and Built Environment, 27(3), 348-368. https://doi.org/10.1177/1420326X16674764

Si, J., \& Marjanovic-Halburd, L. (2018). Criteria weighting for green technology selection as part of retrofit decision making process for existing non-domestic buildings. Sustainable Cities and Society, 41(July 2017), 625-638. https://doi.org/10.1016/j.scs.2018.05.051

Si, J., Marjanovic-Halburd, L., Nasiri, F., \& Bell, S. (2016). Assessment of buildingintegrated green technologies: A review and case study on applications of MultiCriteria Decision Making (MCDM) method. Sustainable Cities and Society, 27, 106-115. https://doi.org/10.1016/j.scs.2016.06.013

Sound-, W. E. B. T., Skills, D., For, A. R. E. I., Sound-, T., Skills, D., Important, A. R. E. E., ... Affect, D. T. (2015). CHOOSING BY ADVANTAGES | 21.0 Why, 3-5.

Suhr, (1999). The Choosing By Advantages Decision-making System. Westport, CT, Quorum.

Tagliabue, L. C., Di Giuda, G. M., Villa, V., De Angelis, E., \& Ciribini, A. L. C. (2018). Techno-economical analysis based on a parametric computational evaluation for decision process on envelope technologies and configurations evaluation for decision process of envelope technologies and configurations. Energy and Buildings, 158, 736-749. https://doi.org/10.1016/j.enbuild.2017.10.004

Tahsildoost, M., \& Zomorodian, Z. S. (2015). Energy retrofit techniques: An experimental study of two typical school buildings in Tehran. Energy and Buildings, 104, 65-72. https://doi.org/10.1016/j.enbuild.2015.06.079

United Nations. (2009). Buildings and Climate Change: Summary for Decision Makers. Buildings and Climate Change: Summary for Decision-Makers, 1-62. https://doi.org/10.1127/0941-2948/2006/0130

US DOE (2019). "Retrofit Existing Buildings." United States Department of Energy (US DOE); Washington DC. https://www.energy.gov/eere/buildings/retrofitexisting-buildings. Visited 5 May 2019.

Wang, Q., \& Holmberg, S. (2014). A methodology to assess energy-demand savings and cost effectiveness of retrofitting in existing Swedish residential buildings. Sustainable Cities and Society, 14(C), 254-266. https://doi.org/10.1016/i.scs.?.014.10.007

Wang, Q., Lee, B. D., Augenbroe, G., \& Paredis, C. J. J. (2017). An application of normative decision theory to the valuation of energy efficiency investments under uncertainty. Automation in Construction, 73, 78-87. https://doi.org/10.1016/j.autcon.2016.09.005

Zheng, D., Yu, L., Wang, L., \& Tao, J. (2019). Integrating willingness analysis into investment prediction model for large scale building energy saving retrofit: Using fuzzy multiple attribute decision making method with Monte Carlo simulation. Sustainable Cities and Society, 44(October 2018), 291-309. https://doi.org/10.1016/j.scs.2018.10.008 